\title{
Notas sobre ensino superior e formação de professores no norte e nordeste do estado de Santa Catarina (1960-1970)
}

\author{
Ilanil Coelho* \\ Fernando Cesar Sossai**
}

Existem fenômenos de recorrências por toda parte: o tempo corre e o tempo cura, ele traz novidades e recupera o que só pode ser reconhecido à distância. [...] Apenas se reconhecermos aquilo que pode se repetir a qualquer momento - mesmo que nem sempre ao mesmo tempo - seremos capazes de mensurar aquilo que é realmente novo em nosso tempo. Talvez seja menos do que imaginemos. Mas esse pouco é decisivo. (Koselleck, 2014, p. 246)

* Graduada em História pela Pontifícia Universidade Católica de São Paulo (PUC-SP). Mestre em Ciências Sociais pela Universidade Federal de São Carlos (UFSCAR). Doutora em História pela Universidade Federal de Santa Catarina (UFSC). Docente do curso de História e do Programa Pósgraduação em Patrimônio Cultural e Sociedade da Universidade da Região de Joinville (Univille). Coordenadora do Centro Memorial e do Laboratório de História Oral da Univille. Líder do grupo de pesquisa Cidade, Cultura e Diferença (gpccd.org).E-mail: ilanilcoelho@gmail.com.

** Graduado em História pela Universidade da Região de Joinville (Univille). Mestre e Doutor em Educação pela Universidade do Estado de Santa Catarina (UDESC). Docente do curso de História e do Programa Pós-graduação em Patrimônio Cultural e Sociedade da Univille. Coordenador do Centro Memorial e do Laboratório de História Oral da Univille. Vice-líder do grupo de pesquisa Cidade, Cultura e Diferença (gpccd.org).E-mail: fernando.sossai@univille.br. 


\section{Introdução}

A epígrafe escolhida para abrir este artigo exprime parte de nossas intençốes ao escrevê-lo. Será que nossas vidas ou uma instituição de ensino superior são mesmo governadas sob império absoluto de um presente cada vez mais efêmero, contingente, ansioso e seduzido pela novidade? Ầ essa experiência do e com o tempo presente, por que revolver o passado para acrescentar uma escrita sobre a história de uma universidade? Talvez porque queiramos "mensurar aquilo que é realmente novo em nosso tempo".

O objetivo deste artigo é compartilhar parte dos resultados de um projeto de pesquisa sobre a história da Universidade da Região de Joinville (Univille) entre 1965 e 2015, realizado durante os anos de 2013 a 2016, que teve como base o levantamento e a análise de um conjunto documental disponível nos acervos do Centro Memorial (CMU), do Arquivo Central e do Laboratório de História Oral (LHO) da Univille e do Arquivo Histórico de Joinville (AHJ); também de trabalhos realizados por docentes e discentes que tiveram a instituição como objeto de suas teses e dissertaçóes; e de fontes bibliográficas sobre a história, a educação no Brasil e o papel da universidade no tempo presente. ${ }^{1}$

Aolongo de todo nosso escrito, procuramos colocar em diálogo os documentos institucionais que pesquisamos junto aos referidos acervos com entrevistas orais produzidas com um ex-dirigente da Univille (realizada em 1999) e com dois exprefeitos de Joinville, realizadas pelas professoras Dúnia Anjos de Freitas e Eneida Raquel S. Thiago no âmbito de um projeto sobre a história política de Joinville e região, desenvolvido entre 1978 e 1996, que resultou numa coleção totalizando 18 entrevistas gravadas em 43 fitas cassetes. Todas as entrevistas utilizadas neste artigo encontram-se disponíveis à consulta pública no acervo do LHO/Univille. ${ }^{2}$

É importante ainda registrar que as entrevistas com os ex-prefeitos foram inicialmente produzidas como parte das estratégias de um curso realizado pelas professoras Dúnia e Raquel junto ao Departamento de História da Universidade Federal de Santa Catarina (UFSC). Esse curso, ocorrido em 1981, contou com o financiamento da Organização dos Estados Americanos (OEA), dirigindo-se à formação de laboratórios de História Oral em implantação nos estados de Santa Catarina (SC) e Rio Grande do Sul (RS). Nesse mesmo ano, a direção da então

1 Tratou-se do projeto "Comemore Univille: 50 anos da Educação Superior em Joinville Região", financiado pelo Fundo de Apoio à Pesquisa (FAP/Univille), e coordenado pelos professores Fernando Cesar Sossai e Ilanil Coelho.

2 O acervo do LHO/Univille é decorrente de doação de entrevistas realizadas por pesquisadores de diferentes áreas de conhecimento, vinculados ou não, à Univille. Hoje, 643 entrevistas integram o acervo desse Laboratório, catalogadas em 42 coleções. A esse respeito ver Coelho e Sossai (2016). 
Fundação Educacional da Região de Joinville (Furj), atual Univille, aprovou e deu início ao projeto de implantação de um laboratório de História Oral na Instituição. Em 1982, o LHO/Univille foi oficialmente criado, o que possibilitou às professoras Dúnia e Raquel formalizarem o projeto de História Oral intitulado "Biografias dos ex-prefeitos de Joinville no século XX". Desse modo, as entrevistas decorrentes desse projeto contribuíram tanto para a criação do LHO/Univille, quanto para justificar a pertinência e a razão de ser de um laboratório voltado à produção de fontes orais sobre a história de Joinville e região. Além disso, sinalizavam um trabalho articulado de uma rede de pesquisadores de História Oral que se estabeleceu no Brasil desde 1975, envolvendo outras iniciativas institucionais, como o Laboratório de História Oral (LABHORAL) do Programa de Pós-Graduação (PPG) em História da UFSC, coordenado pelo professor Carlos Humberto Pederneiras Corrêa, e o Programa de História Oral do Centro de Pesquisa e Documentação de História Contemporânea do Brasil (CPDOC) da Fundação Getúlio Vargas (FGV). Os primeiros projetos dessa rede voltaramse ao estudo sobre a trajetória e o desempenho das elites locais e nacionais. Com vistas a compreender a formação e os caminhos do Estado Brasileiro, buscavase entrevistar personagens de reconhecida importância, cujas histórias de vida subsidiariam o conhecimento sobre as influências políticas e intelectuais por elas exercidas.

Por outro lado, em âmbito local, o projeto "Biografia dos ex-prefeitos de Joinville no século XX" também foi concebido e articulado a outra instituição da cidade: o AHJ. À época, essa instituição possuía um vasto acervo composto por documentos escritos em alemão, inclusive em gótico, que se referiam à vinda e ao estabelecimento de imigrantes germânicos na cidade a partir de meados do século XIX. Ao AHJ estava vinculada a tradutora e escritora Elly Herkenhoff, que ficou encarregada por escrever as biografias daqueles que teriam ocupado o cargo de administradores do núcleo colonial e, após a elevação a município, os que foram prefeitos de Joinville durante o século XIX, baseando-se em cartas, diários e outras fontes do acervo do AHJ que aludiam à vida e obra dessas lideranças. Diante da escassez de fontes com as mesmas características referentes à trajetória dos prefeitos de Joinville no século XX, o LHO/Univille ficou responsável por produzir uma coleção de entrevistas com os ex-prefeitos ou com familiares próximos de ex-prefeitos já falecidos. Em que pesem as possíveis críticas em relação a essa disposição inicial de associar a História Oral com uma história política voltada para as elites e os notáveis, ${ }^{3}$ o fato é que, na Furj, essa primeira iniciativa contribuiu para que outros docentes e estudantes em formação, especialmente dos

3 A esse respeito, ver os conhecidos trabalhos de Alberti (1989) e Amado e Ferreira (1996). 
cursos de licenciatura, também começassem a desenvolver projetos de História Oral. Foi nesse percurso que o LHO/Univille passou a se defrontar e a promover discussões sobre as tensas relações entre memória e história, bem como sobre as novas possibilidades analíticas combinando-se fontes orais e escritas.

Para os propósitos deste artigo, tal digressão se fez necessária para aludir a uma questão metodológica desafiadora: como utilizar entrevistas já produzidas para enfrentar os nossos próprios problemas de investigação? Em texto publicado em 2013, o historiador Alexander Freund destaca que diante da existência de um "vasto arquivo global de histórias de vida” à disposição dos pesquisadores, podemos considerar as entrevistas realizadas por outrem como "história oral gerada em processo" (Freund, 2013, p. 29-30). Tal qual outras fontes, elas foram produzidas para outros fins e em outros contextos. Contudo, por serem entendidas como "construçóes sociais complexas" afetadas por subjetividades, as entrevistas sinalizam "múltiplas camadas de significado", as quais estão ligadas aos propósitos que as moveram, aos desejos de verdade agenciados pelos entrevistados e entrevistadores, aos dilemas por eles visados no presente em que falam e dialogam, aos sentidos atribuídos aos acontecimentos e às experiências do passado que destacam e, no caso das entrevistas que fazemos uso nesta escrita, às interpretações e explicações dos entrevistados sobre o que fizeram em relação ao ensino superior de Joinville e região e à formação de professores para a educação básica.

Nessa direção, também se fez necessário aprofundarmos o debate teóricometodológico sobre história institucional tomando como referência o trabalho do historiador Juan Daniel Flórez Porras (2011).

De acordo com esse autor, a história institucional é concernente, em primeiro lugar, à criação e à trajetória de entidades definidas por marcos jurídicos conformados pelo poder do Estado. Em segundo lugar, está implicada na consideração das suas estruturas administrativas, já que essas são desdobramentos dos ordenamentos jurídicos vigentes ao longo do tempo em que desenvolve suas funçóes e em compasso com as dinâmicas políticas e culturais das sociedades que lhes são referências. Como problemática histórica, sugere o autor que a escrita histórica sobre instituiçóes ora é carregada por uma dimensáo laudatória ora, em contraposição, dominada por enfoques temáticos insulares (ainda que interessantes), isto é, enfoques desconectados entre si e destituídos de uma problemática histórica que os articule numa "história comum" (Porras, 2011, p. 21). O desafio seria, pois, produzir uma história institucional que englobasse os aspectos suscitados pelo autor, mas, sobretudo, que construísse articulaçóes entre a história da instituição com problemáticas históricas relevantes socialmente para o tempo presente.

$\mathrm{Na}$ esteira dessa perspectiva, cumpre dizer que a história da Univille tem 
como marco inicial a criação da Faculdade de Ciências Econômicas de Joinville (FCEJ), em 1965 pela Comunidade Evangélica de Joinville, faculdade essa que foi incorporada à Fundação Joinvilense de Ensino (Fundaje), instituída pelo poder público municipal em 1967. Em 1971 a denominação Fundaje foi alterada para Fundação Universitária do Norte Catarinense (Func), a qual em 1975 passou a ser denominada Furj, atual mantenedora da Univille. Contudo, enquanto problema histórico, coube-nos indagar as razóes que levaram a tais mudanças e as questóes que foram colocadas em jogo pelos segmentos internos (professores, técnicos administrativos e alunos) e pelos grupos externos que, direta ou indiretamente, protagonizaram, articularam, se confrontaram, vislumbraram inserçóes e interaçóes com as sociedades local e regional em diferentes contextos e também construíram possibilidades ou planos de futuro que visavam defender e fortalecer a instituição enquanto espaço de conhecimento, de aprendizagem, de enfrentamento de problemas, de experimentação democrática e de crítica social.

Para os propósitos deste artigo, realizamos um recorte no âmbito das intençôes e tensóes que, no transcurso das décadas de 1960 e 1970, incidiram na criação e oferta de cursos de graduação direcionados à formação de professores para o exercício do magistério da educaçáo básica na região Norte/Nordeste do estado de Santa Catarina.

$\mathrm{O}$ artigo encontra-se estruturado em três partes. Na primeira, apresentamos uma análise do processo de constituição da então FCEJ, em 1965. A problemática envolve as motivaçóes que levaram lideranças políticas, empresariais e educacionais a criarem o ensino superior na região, bem como as razóes que recaíram na escolha para que esse pioneirismo fosse protagonizado por um curso da área de conhecimento em Ciências Sociais Aplicadas. Em seguida, passamos a um debate sobre a constituição, dois anos mais tarde (1967), da Fundaje, incorporando os trabalhos da FCEJ, e à enunciação de sua autodefinição como polo de formação superior da comunidade regional. Nessa direção, procuramos refletir sobre um dos desdobramentos que remetem às motivaçóes e à autodefinição institucional, qual seja, o papel, perspectivado pelas lideranças políticas, a ser desempenhado pela Fundaje na oferta pioneira de cursos de formação de professores no norte e nordeste catarinense. Desse modo, no processo de interiorização do ensino superior, ocorrido nos primeiros anos da década de 1960, nosso propósito é refletir sobre os interesses e os jogos políticos que incidiram na criação da Faculdade de Filosofia, Ciências e Letras de Joinville (FFCLJ) que passou, em 1968, a ofertar os cursos de licenciatura em Geografia, História, Letras e Matemática. Na terceira e última parte, finalizamos o artigo com um breve debate a respeito das perspectivas de universidade e de formação de professores que transpassaram a constituição da Fundaje e de sua FFCLJ, em 1968, com o intuito de, como nos sugere Koselleck, perquirir, à distância, o que se colocava realmente como novidade quando, 
naquele momento, se aludia à oferta local de cursos de licenciatura.

\section{A criação do ensino superior no norte e nordeste de Santa Catarina}

O ensino superior em Joinville, como apontado anteriormente, tem como marco a instalação oficial da FCEJ (Figura 1), ocorrida em 1965 por iniciativa da Comunidade Evangélica de Joinville. Inicialmente, coube-nos perguntar: quais interesses, motivos e objetivos concorreram para tal esforço? Com base na obra do historiador Apolinário Ternes (1986, p. 127) é possível sugerir que a criação da faculdade foi uma das respostas ao contexto de crise do Colégio Bom Jesus, ${ }^{4}$ desencadeada em 1955, quando passou a enfrentar uma "escassez de recursos, com decréscimo de matrículas e sobretudo de depreciação de seu patrimônio físico”.

Em 1963, a Sociedade Civil Filantrópica Colégio Bom Jesus, então

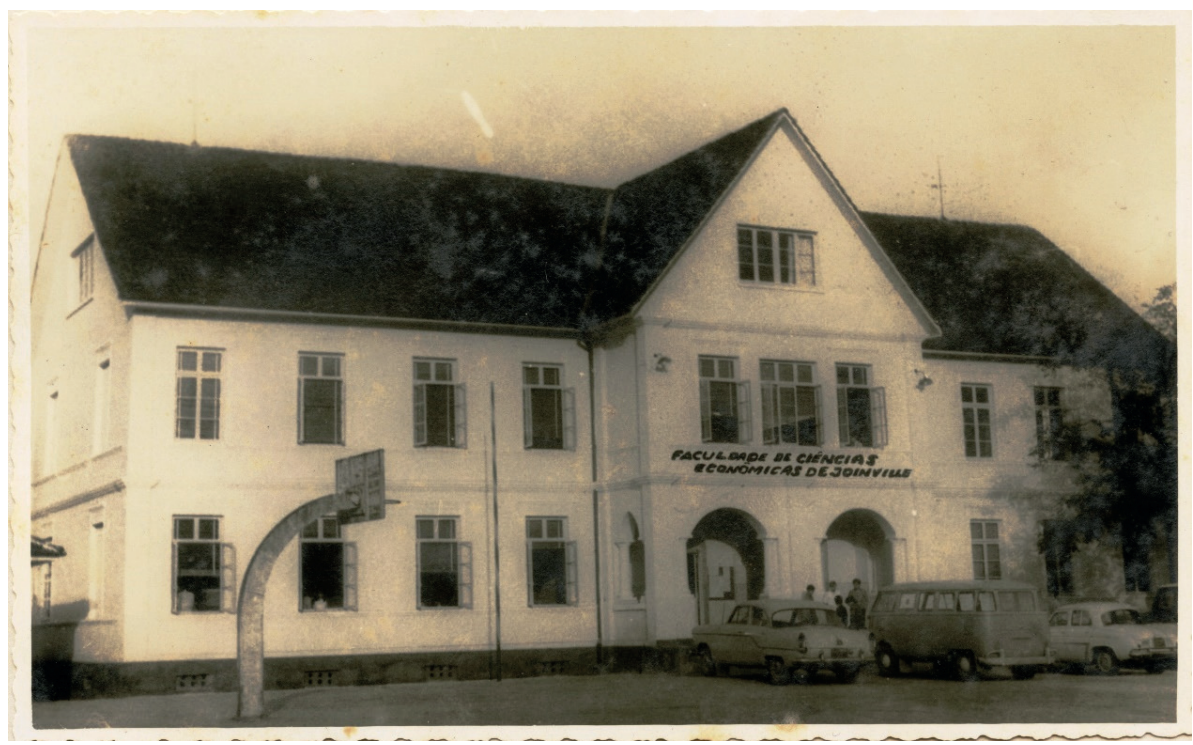

Figura 1 - Prédio da Faculdade de Ciências Econômicas de Joinville (1965) Fonte: Acervo do Centro Memorial e LHO/Univille.

4 Conforme Ternes (1986), a história do Colégio Bom Jesus tem como marco a instalação da Deutsche Schule (Escola Alemã) em 1866, escola particular criada para atender demandas de imigrantes germânicos residentes em Joinville. Mais informações sobre o Colégio Bom Jesus, ver: http://colegiobonja.com.br/ quem-somos/. 
mantenedora da FCEJ, decidiu pela sua dissolução. Contudo, no curso dos acontecimentos, esboçaram-se duas alternativas. A primeira consistia na venda de todo o patrimônio, incluindo as autorizaçóes de cursos, para um grupo de educadores de Curitiba. A segunda, que acabou sendo concretizada, resultou na aquisição do Bom Jesus pela Comunidade Evangélica de Joinville, que adquiriu o prédio do antigo Hotel Paris, localizado nas imediaçóes do colégio, para abrigar a FCEJ.

De acordo com Ternes (1986, p. 132), a ideia de instalar o primeiro curso superior na cidade já vinha sendo discutida pela educadora Anna Maria Harger, então diretora do Colégio Bom Jesus, por professores, pais de alunos e algumas lideranças políticas de Joinville, até ganhar impulso em 1963, quando a Comunidade Evangélica designou o prof. Hamilton Sidney Alves de Carvalho para encaminhar os trâmites burocráticos de instalação do curso. Nessa direção, em entrevista concedida à professora Dúnia Anjos de Freitas, o Sr. Helmuth Ernesto Fallgatter (1909-2001), prefeito de Joinville durante os anos de 1961 a 1966, sinalizou que a criação da FCEJ foi possível graças aos variados apoios locais que recebeu, em especial de "destacadas personagens do Município", "principalmente, [...] o seu Hilário Buschle, o irmão do Baltasar Buschle" (19181961), um importante político local que havia ocupado o cargo de prefeito de Joinville no período de 1958 a 1961 (Helmuth Ernesto Fallgatter, 1984).

Nascido em Curitiba, o Sr. Helmuth Ernesto Fallgatter contou que sua família mudou-se para Joinville quando ele tinha seis anos. Estudou até a $8^{a}$ série no Colégio Bom Jesus, então Escola Alemã. Lembrou que, durante a Segunda Guerra, a Escola Alemã foi alvo de intervençôes governamentais injustas, decorrentes das medidas tomadas pelo presidente Getúlio Vargas e pelo governador de Santa Catarina, Nereu Ramos, para nacionalizar o ensino. Mesmo reconhecendo que, no seu tempo, tinha "só duas horas por semana de português", insuficientes para aprender e praticar a língua portuguesa, a proibição do uso da língua alemã e os métodos adotados para efetivar tal proibição foram "totalmente errados". Em primeiro lugar, porque na maior parte da cidade a populaçáo só falava alemão. As crianças chegavam à escola quando já tinham sido ensinadas a falar alemão pelos pais e avós. Em segundo lugar, porque não havia professores e escolas que ensinavam português ou em português. Essas lembranças foram narradas quando, na entrevista, ele foi indagado sobre a contribuição de sua gestão para a educação no município. Disse ele: "o ensino estava bastante fraco". Ainda durante a guerra, as crianças começaram a aprender o português, principalmente com aulas particulares, mas faltavam escolas. Por isso, a construção de 34 escolas municipais teria sido sua prioridade para responder à demanda existente no ensino básico. Ademais, enfatizou ele em sua entrevista: "ênfase especial foi dado ao ensino superior, o qual antes de nossa gestão, quer dizer, antes de 1959, não existia em 
Joinville. Conseguimos inaugurar a Faculdade de Ciências Econômicas”, junto ao Colégio Bom Jesus, respondendo desse modo a "uma necessidade da própria comunidade" (Helmuth Ernesto Fallgatter, 1984).

Para além disso, conforme apontado por Vanessa de Oliveira Collere (2002, p. 64), as discussões da Sra. Anna Maria Harger com os professores do Colégio Bom Jesus projetavam a faculdade como uma espécie de prolongamento do curso técnico de Ciências Contábeis (que já era ofertado pela própria instituição). Por outro lado, destaca a autora que nem todos da "comunidade empresarial" se mostravam otimistas à criação da faculdade. Isso porque, de acordo com um dos seus entrevistados, alguns empresários avaliavam apenas os efeitos negativos da implantação, em 1960, da universidade federal na capital do estado: "Do dia pra noite... transformou Florianópolis! E eles viam isso e não queriam pra Joinville" (Collere, 2002, p. 64). Sugere o entrevistado que, mais do que vantagens, a instalação do ensino superior poderia modificar profundamente a paisagem e os comportamentos urbanos, acarretando mudanças que poderiam comprometer a vida local. Mesmo em meio a sentimentos de recusa de parte da elite empresarial joinvilense, o projeto de implantação da FCEJ foi adiante.

Ao rememorar esse processo de constituição da FCEJ, o professor Achiles Júlio Schünemann (1999) salientou que o "curso de Ciências Econômicas, no Colégio Bom Jesus, na Comunidade Evangélica, foi o primeiro curso superior instalado fora da capital" (Florianópolis). Docente contratado pela Fundaje em 1968 para trabalhar nos cursos de Ciências Econômicas e Matemática, o Sr. Achiles mudou-se de Curitiba para Joinville em 1965, passando a residir em uma casa ao lado do Colégio Bom Jesus. Além de professor da Fundaje, Func e Furj, ele também foi Diretor-geral da Furj durante os anos de 1988 e 1989. Segundo ele, na cidade, havia apenas um "curso de Engenharia... uma Engenharia Operacional, que [...] também iniciou em 1965, mas foi logo após ao curso de Ciências Econômicas da Faculdade de Joinville" (Achiles Júlio Schünemann, 1999).

Ainda a esse respeito, na "Ata de fundação da Faculdade de Ciências Econômicas da Cidade de Joinville", datada de "9 de março de 1964" - dia legalmente instituído como aniversário do município -, registrou-se a realização de uma "sessão solene" para "fundação da Faculdade", que contou "com a presença das autoridades e elevado número de pessoas da sociedade local” (FCEJ, 1964). A sessão foi presidida pelo Sr. Raul Schmidt, 5 que fez um relato "das démarches havidas" para concretizar a empreitada. Perante o "acentuado índice

5 Diretor da Fundição Tupy e fundador Escola Técnica Tupy, inaugurada em 1959. No final dos anos 1950, a Tupy era a maior indústria de Santa Catarina. 
industrial da comuna", a formação de futuros economistas seria relevante não apenas localmente, como também para a expansão do comércio e da indústria em âmbito regional. Tal orador ainda ressaltava que, "para o funcionamento normal dessa Faculdade, seria bem fácil a formaçáo de seu corpo docente", bem como "não surgiria qualquer obstáculo na marcha do processo junto ao competente Ministério" (FCEJ, 1964). Inicialmente o curso funcionaria no próprio edifício do Colégio Bom Jesus, no período noturno, a partir do "exercício de 1965". No dia seguinte a essa solenidade, foi designado como diretor o prof. Hamilton Sidney Alves de Carvalho.

De fato, o pedido de autorização para o funcionamento da faculdade foi solicitado ao Ministério da Educação e Cultura (MEC) ainda em 1964, sem, contudo, obter êxito. No Conselho Federal de Educação (CFE), várias diligências foram baixadas para averiguar a pertinência de a cidade possuir um curso superior de Economia, a capacidade financeira da mantenedora e a situação do corpo docente. O primeiro vestibular aconteceu em fevereiro de 1965, e, em 15 de março do mesmo ano, foi proferida a aula inaugural do curso para 50 acadêmicos matriculados. Dessa forma, o problema foi agravado, pois o CFE ainda não havia emitido autorização para iniciar as atividades. Pela documentação é possível tanto constatar o esforço da equipe responsável por responder a todos os questionamentos do CFE, quanto vislumbrar a rede e as mudanças políticas que envolveram tal questáo, pois o curso só foi autorizado definitivamente em 18 de março de 1969 (BRASIL, 1969), ${ }^{6}$ ou seja, no ano da formatura da primeira turma.

No primeiro parecer do CFE foi denegada a autorizaçáo para que se esclarecesse a natureza da mantenedora e do curso a ser ministrado. Realizada a primeira diligência, que constatou tratar-se de mantenedora de natureza privada e de curso de graduação, um segundo parecer apontou: 1) "não haver interesse social" na formaçáo de economistas; 2) a necessidade para que fossem "esclarecidas as situaçôes relativas ao corpo docente, em sua grande maioria residente em Curitiba"; 3) a apuração sobre o funcionamento irregular da faculdade "sem a devida autorização" (Brasil, 1968).

Com relação ao item 3, a Comissão Verificadora do CFE concluiu que a faculdade "não aguardou a manifestação do Conselho Federal de Educação por desconhecimento", mas que foi inspecionada por esse órgáo logo após a realização do primeiro vestibular. Ainda que tenha havido um lamentável "ato irregular", constatou-se que "está, agora, a Faculdade em condiçóes de ter o seu

6 Após a autorização, enviou-se o processo de reconhecimento da Faculdade ao CFE, conforme Relatório de Atividades da Fundaje encaminhado ao prefeito de Joinville, Harold Karmann em 15 de janeiro de 1971. 
funcionamento autorizado" (Brasil, 1968).

Quanto à situação do corpo docente, ainda que tenham sido satisfeitos os questionamentos do CFE com a verificação de que os professores residentes em Curitiba tinham compatibilidade de horário e condiçóes satisfatórias de deslocamento para ministrar as aulas programadas, Collere (2002) nos possibilita conhecer outras nuanças que atravessaram esse problema. Segundo as entrevistas realizadas por ela, o grupo que organizava a faculdade recorreu inicialmente à Universidade Federal de Santa Catarina (UFSC) para compor seu quadro docente. No primeiro contato houve receptividade em dar apoio. Entretanto, num segundo encontro, houve sugestáo para que a Faculdade de Joinville oferecesse um ciclo básico (os dois primeiros anos) e o ciclo profissional seria desenvolvido no curso de Economia da UFSC. Diz Collere (2002) que, rejeitado o modelo, o grupo buscou e concretizou o apoio junto de professores da Universidade Federal do Paraná (UFPR). Tal informação também é evidenciada na entrevista concedida pelo professor Achiles Júlio Schünemann (1999), quando ele mencionou o fato de os primeiros professores da FCEJ, em 1965, gastarem um tempo de "quatro horas" para percorrer a estrada "tão ruim" que "separava Joinville de Curitiba".

Em relação ao item 1, ou seja, ao questionamento sobre a relevância social e regional da formação de economistas, os avaliadores relataram que constataram o que foi informado pela autoridade competente: "Joinville é um centro industrial do país do mais avançado progresso" (Brasil, 1968). Sendo assim, concluem que "não só se deve autorizar o seu funcionamento, como se lhe deve dar o reconhecimento". Ao que tudo indica, a autoridade competente a que se referem os avaliadores é o economista e assessor de planejamento municipal Sr. Heraldo Silva do Valle, signatário de um relatório circunstanciado sobre a relevância da formação de economistas na cidade e na região, constante do processo.

Procurando entender o emaranhado de discursos que compóem o processo de autorização da faculdade, esforçamo-nos, no próximo item deste artigo, por interpretá-los no complexo contexto político-educacional brasileiro do fim dos anos 1950 e do decorrer da década de 1960, articulando outros acontecimentos singulares da história institucional: a criação da Fundaje em 1967 e a implantação da FFCLJ em 1968. De nossa perspectiva, tais acontecimentos conformaram a oferta pioneira de cursos de formação de professores no norte e nordeste catarinense, a qual, supostamente, iria contribuir não somente para a emergência e o desenvolvimento de novos campos de conhecimento nas cidades de atuação da Fundaje. Contribuiria, sobretudo, para a sistemática interiorização do ensino superior no estado de Santa Catarina que, segundo Aguiar (2012, p. 217), inscrevia-se em políticas públicas que, naquele contexto, "estavam profundamente articuladas com interesses regionais privados e fundamentadas na ideia de universidade como discurso para o desenvolvimento". 


\section{A interiorização do ensino superior e a oferta de cursos de formação de professores na região norte-nordeste de Santa Catarina}

Um primeiro aspecto a ser considerado manifesta-se discursivamente nos vários documentos do poder público de Joinville que, ao justificar a pertinência, as funçóes e a abrangência do ensino superior para a cidade e região, insinuam uma espécie de ressentimento e descontentamento de parte da elite política e empresarial local diante da morosidade do governo estadual em interiorizar o ensino superior.

Ocorre que, em 1960, foi eleito pelo Partido Social Democrático (PSD) o governador Celso Ramos. Conforme Goularti Filho (2002, p. 192-193), a sua vitória deveu-se ao fato de seu programa de governo estar alinhado tanto à noção de um Estado planejador de cunho econômico-desenvolvimentista quanto aos anseios do empresariado catarinense explicitados no decorrer de um grande "Seminário Socioeconômico", promovido pela Federação das Indústrias do Estado de Santa Catarina (Fiesc) ${ }^{7}$ entre 1959 e 1960. O documento resultante desse seminário apontou os problemas enfrentados para integrar a economia e consolidar a industrializaçáo de Santa Catarina, bem como a necessidade de "novos arcabouços institucionais, financeiros e novos investimentos em infraestrutura" (Goularti Filho, 2002, p. 206). Incorporado no Plano de Metas do Governo (Plameg) da administração de Celso Ramos (1961-1965), a área da educação ocupava a terceira posição no orçamento previsto para sua execução, atrás das áreas rodovias e energia. Contudo, a interiorizaçáo do ensino superior pelo governo estadual apenas começou a ser concretizada em agosto de 1965, quando a Faculdade de Engenharia de Joinville (FEJ) "iniciou suas atividades, com o curso de Engenharia de Operação, modalidade Mecânica de Máquinas e Motores". 8

Antecederam a essa iniciativa estadual, além da FCEJ, outras faculdades criadas pelos poderes públicos municipais de Blumenau, a Universidade Regional de Blumenau (FURB), Lei Municipal n. ${ }^{\circ} 1.233 / 64$, de 5 de março de 1964; de Itajaí, a Universidade do Vale do Itajaí (Univali), Lei Municipal n. ${ }^{\circ}$ 599/64, de

Conforme Goularti Filho (2002, p. 192-193), a Fiesc, fundada em 1950, indicou Celso Ramos como primeiro presidente, "em função do seu forte vínculo com a política estadual e nacional [...] e do apoio que recebeu de Euvaldo Lodi, presidente nacional da CNI (Confederação Nacional da Indústria) que coordenou o Seminário Socioeconômico".

8 História da instituição. Disponível em: <https://www.udesc.br/cct/sobreocentro/historia>. Acesso em: 22 jun. 2020. 
22 de setembro de 1964; e de Tubarão, a Universidade do Sul de Santa Catarina (Unisul), Lei Municipal n. ${ }^{\circ}$ 353, de 25 de novembro de 1964.

É nesse quadro que podemos articular as iniciativas do Sr. Nilson Wilson Bender quando, em 1966, eleito pela Uniáo Democrática Nacional (UDN), assumiu a Prefeitura de Joinville e instituiu um grupo de trabalho (Decreto n. ${ }^{\circ}$ 1.624, de 30 de dezembro de 1966) com o objetivo de construir um projeto para a expansão do ensino universitário. Em entrevista concedida à Dúnia Anjos de Freitas, Nilson Bender destacou que era imperativo elevar os índices de escolarização e profissionalização dos jovens joinvilenses. De início, seria necessário institucionalizar a Fundaje (Figura 2). O segundo passo seria viabilizar a criação da FFCLJ, pois "nós constatamos que, dos trezentos e tantos professores [...] que

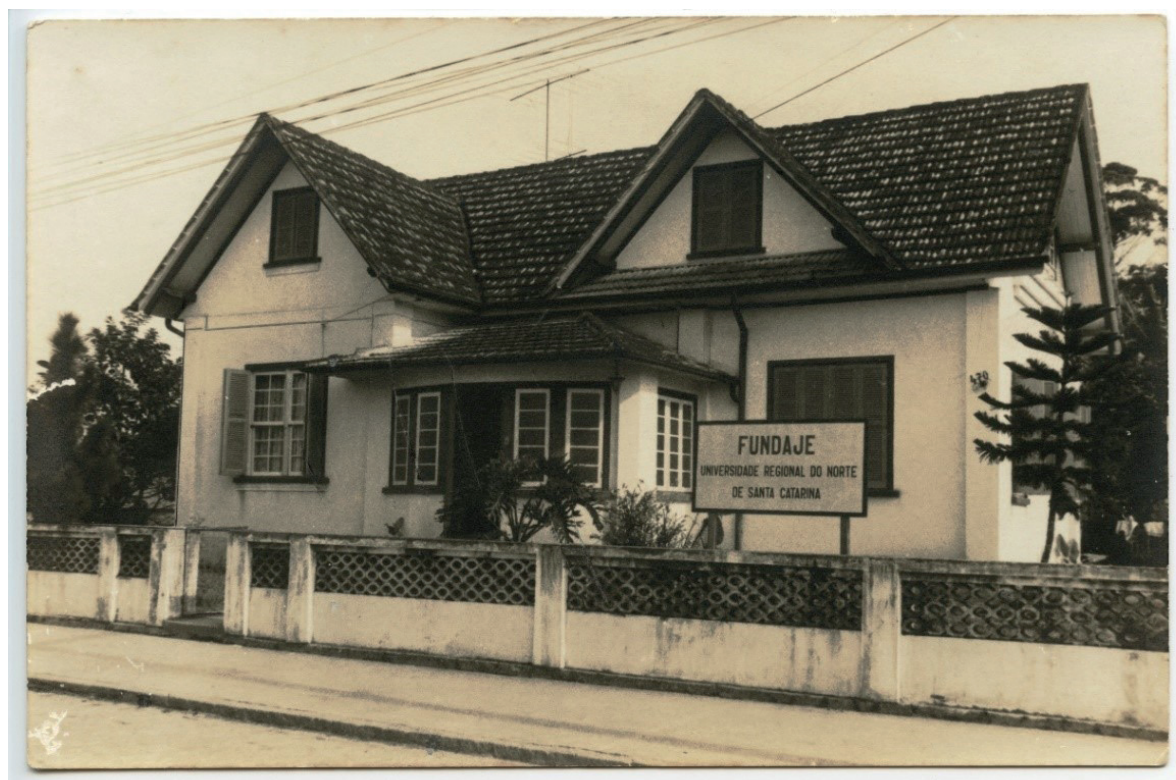

Figura 2 - Sede administrativa da Fundação Joinvilense de Ensino, em 1968 Fonte: Acervo do Centro Memorial e LHO/Univille.

lecionavam nos ginásios da região, tinha apenas dois com título universitário". Além de vislumbrar "um grande mercado para a formação de professores", a FFCLJ deveria "se constituir num centro de formação cultural para outras pessoas que não quisessem seguir a profissão de professor" (Nilson Wilson Bender, 1983).

Para tanto, contou o Sr. Nilson Bender que, já em 1967, tinha assinado duas leis. A primeira foi a Lei $n .^{\circ} 871$, de 17 de julho, que autorizava o prefeito 
a constituir a Fundaje e subvencioná-la. Diz Nilson Wilson Bender (1983): "Aí nós destinamos $1 \%$ do orçamento municipal para subvencionar a Fundaje [...]. Mas $1 \%$ era na fase inicial com uma... com uma faculdade. A ideia era ir até 3\% para as demais faculdades". A segunda, foi a Lei n. ${ }^{\circ}$ 905, de 14 de novembro,

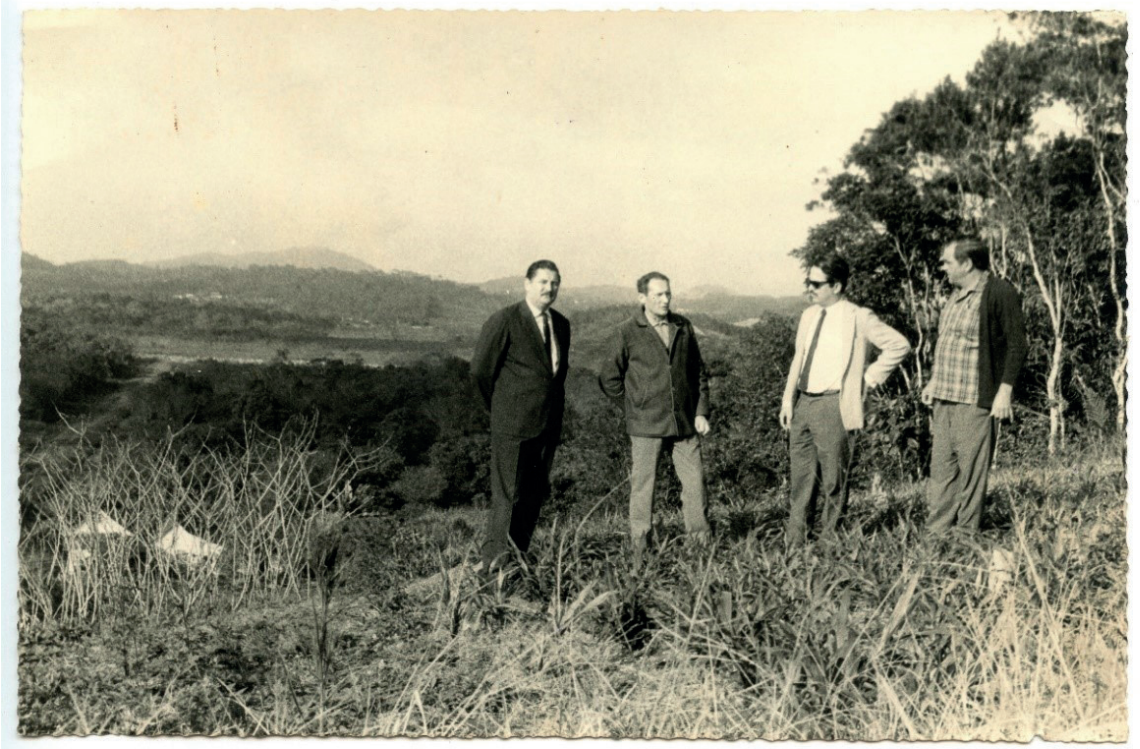

Figura 3 - Visita ao terreno que abrigaria as futuras instalações do Campus Universitário de Joinville (final dos anos 1960). Da esquerda para a direita: prefeito Nilson Wilson Bender (de terno e gravata), Werner Frederick, Heraldo do Valle e Osni Toentapp Fonte: Acervo do Centro Memorial e LHO/Univille.

autorizava o executivo municipal a doar uma área de terras para a construçáo do futuro campus (Figura 3).

Ademais, ainda seria necessário vincular à Fundaje a FCEJ, que, à época, atravessava dificuldades. Ao que tudo indica, as dificuldades a que se refere o prefeito se ligavam tanto aos contínuos questionamentos do CFE para autorizá-la quanto à crítica situação financeira da Comunidade Evangélica para mantê-la. Tal suposição ganha sentido quando se analisa o relatório circunstanciado do assessor de planejamento municipal Sr. Heraldo Silva do Valle (1968), enviado ao CFE em meados de 1968 e que, entre outros argumentos, destacava que, tão logo fosse regularizada, o poder público municipal integraria a faculdade de iniciativa privada à recém-criada Fundaje. Também nesse relatório é sinalizado que desde o início 
a formação de economistas visou corrigir uma situação de "desproporcionalidade convincente", visto que, mais do que a capital Florianópolis, que já contava com uma universidade, Joinville havia registrado no período de 1960 a 1964 o maior índice de crescimento populacional, em decorrência da vinda de migrantes atraídos pelas oportunidades de trabalho em suas 468 indústrias, tornando o ensino superior "indispensável e imprescindível, para atender ao crescimento incessante do complexo industrial e a adequação perfeita dos recursos humanos exigidos dia a dia" (Valle, 1968, p. 4).

O município, ao despontar como o primeiro do estado em arrecadação tributária, não poderia mais comprometer seu "progresso" com a evasão de jovens para a capital e para os estados vizinhos (Paraná e Rio Grande do Sul) em busca de formação, pois poucos retornavam "à sua terra de origem”, terra essa sempre "carente de mão de obra qualificada" (Valle, 1968, p. 17). Por outro lado, ainda segundo o relatório, desde o início de seu funcionamento o curso teve sua abrangência ampliada, destacando que mais ainda seria ao ser incorporado pela Fundaje, pois "a teoria do desenvolvimento define com clareza e substância o desenvolvimento regional gerado pelo centro polarizador, com maior amplitude para a periferia e em menor escala desta para aquele". Assim, a formação de economistas também estava beneficiando os municípios polarizados por Joinville, "a fim de que possam dotar as classes dirigentes de pessoal qualificado para promover o seu desenvolvimento" (Valle, 1968, p. 17).

Isso nos remete à necessária reflexão sobre a história da Fundaje de maneira entrelaçada às mudanças operadas no campo educacional por força das transformaçóes da sociedade brasileira a partir da segunda metade da década de 1960. À época, o país já estava submerso numa ditadura, justificada pelos "Comandantes em Chefe do Exército, da Marinha e da Aeronáutica" como a única via para "restaurar no Brasil a ordem econômica e financeira e tomar as urgentes medidas destinadas a drenar o bolsão comunista" (Brasil, 1964). A educação, segundo Germano (2008), foi uma das principais áreas atingidas. Além da perseguição a professores e da repressão aos movimentos estudantis, o governo, com base na doutrina de segurança nacional e na ideia de "Brasil potência", implantou um grupo de trabalho que contou com a assessoria da United States Agency for International Development (USAID), cujas recomendaçóes apontavam para a necessidade de mudanças no perfil da universidade baseadas no modelo empresarial. Além de visar ao desenvolvimento econômico do Brasil, a reforma educacional deveria ser um instrumento de formação de mão de obra especializada, disciplinada e com valores pátrios inculcados. Contudo, o principal desafio seria expandir a formação superior, contendo despesas.

Para Germano (2008), os discursos políticos, como quaisquer outros, 
podem ser concebidos como atos de linguagem que são movidos e movem o mundo social, possibilitando-nos apreender algumas das ideias e valores que circulam num tempo histórico. Além disso, os discursos políticos remetem-nos a um campo de práticas de poder que se deixam ver, por exemplo, na forma de leis voltadas à regulação jurídica da vida social ou de doutrinas que buscam explicitar e disseminar aos outros o que julgam ser verdadeiro, inquestionável e imperativo. Desse ponto de vista, é possível analisar as razóes pelas quais o poder municipal, ao justificar a pertinência, a função e a abrangência da FCEJ e da Fundaje, se serviu de termos que procuravam estabelecer coerência e concordância com a rede de discursos dos agentes e das agências da ditadura civil-militar. Assim, podemos presumir que a defesa da municipalidade não buscou apenas convencer, mas também servir-se do que "com clareza e substância" definia, à época, "a teoria do desenvolvimento" (Valle, 1968).

Segundo Bielschowsky (2011, p. 15), até 1980, predominou no Brasil a definição de desenvolvimentismo como um "projeto de industrialização integral como via de superação do subdesenvolvimento, conduzido pelo Estado". Ainda que houvesse correntes e posiçóes políticas distintas, ideologicamente predominaram na noção de desenvolvimentismo alguns pontos comuns, entre os quais se destacam a afirmação da industrialização como eixo central e dinâmico do desenvolvimento e a necessidade de planejamento e de intervenção do Estado para estruturá-lo e fomentá-lo.

Dessa forma, sendo Joinville o polo industrial da região Norte/Nordeste de Santa Catarina, caberia ao poder público envidar todos os esforços para fornecer às indústrias da região as condições necessárias ao seu pleno desenvolvimento. É com base nessa lógica que buscamos refletir sobre o paradoxo que atravessou não apenas a história institucional como a história de outras Instituições de Educação Superior (IES) catarinenses até, pelo menos, a promulgação em novembro de 2013 da Lei n. ${ }^{\circ}$ 12.881, da Presidência da República, que dispóe sobre definição, qualificação, prerrogativas e finalidades das instituiçóes comunitárias de educação superior.

Se atualmente as IES públicas são aquelas mantidas e financiadas pelo Estado e que não cobram matrículas e mensalidades dos alunos, naquele contexto, o caráter público das IES era inscrito pelo próprio ente que as criava, que compunha seu patrimônio e que se comprometia em subvencioná-la. Não havia dessa forma nenhum impedimento na cobrança de mensalidades, tampouco estava em pauta o regime jurídico de contratação de docentes e de técnicos administrativos. A esse respeito, destaca-se que a Universidade do Estado de Santa Catarina (Udesc) até 1989 era também mantida com recursos oriundos da cobrança de mensalidades, quando houve a reforma da Constituição Estadual em consonância com a 
Constituição Federal de 1988. Porém, o que se coloca de maneira problemática é o caráter privatista das universidades e do ensino superior brasileiro que, à época, era inscrito pelo poder público em suas diferentes esferas. Caberia então indagar se esse caráter privatista se restringiu às açôes governamentais.

Em seus "Escritos sobre a universidade", a filósofa Marilena Chauí (2001) destacou que o predomínio dos interesses privados sobre o público, bem como os mecanismos autoritários que incidem sobre as universidades brasileiras, não se restringe ao regime ditatorial dos anos 1960 a 1980, "mas é, antes, a forma mesma de realização da sociedade e da política” no Brasil. Com isso, a autora quer dizer que historicamente construímos uma "sociedade autoritária", sob a qual impera a "naturalização das desigualdades econômicas e sociais" e de suas "formas visíveis de violência” (Chauí, 2001, p. 14). Dessa perspectiva, compreende-se que, enquanto instituição social, a universidade "realiza e exprime" em toda a sua complexidade "a sociedade de que é e faz parte" (Chauí, 2001, p. 14). Por consequência, para nós, a escrita da história institucional implica um esforço de análise não apenas das mudanças da Univille ocorridas através do tempo, mas também das mudanças que num determinado recorte de tempo sincronicamente incidem (ou atuam) sobre sua configuração.

No decorrer das décadas de 1960 e 1970, vários movimentos sociais, especialmente os estudantis, visaram resistir e criticar a ideologia desenvolvimentista e as práticas autoritárias que entáo procuravam formatar o ensino superior e a própria universidade. Ao serem reprimidos, foram, ao mesmo tempo, sendo tomados como referência para o estabelecimento de um conjunto de dispositivos que tencionaram a interiorizaçáo do ensino superior brasileiro, com baixo custo para o Estado, e para a redução e o controle da autonomia universitária. Entre os dispositivos, se encontravam os marcos regulatórios e normativos que visavam à adoção de um modelo empresarial de estruturação e gestáo acadêmicas, à obrigatoriedade de os projetos de curso cumprirem currículos mínimos/comuns e à inclusão de conteúdos predefinidos pelos órgãos federais de educação.

Conforme o Estatuto da Fundaje (FUNDAJE, 1967), sua administração seria exercida por um conselho deliberativo formado por sete membros, todos escolhidos pelo prefeito9", com as seguintes atribuiçóes: "definir os planos de longo prazo", zelar para que fossem cumpridos seus "fins estritamente educacionais", escolher diretores das unidades de ensino e autorizar os seus atos, decidir sobre o quadro de pessoal e "fixar os preços de serviços, as taxas e emolumentos escolares". Contudo, surpreende a informação trazida por Collere (2002) sobre a

9 Dos sete membros, seis eram de sua livre escolha e um "escolhido pelo Prefeito em lista tríplice a ser apresentada pela Associação dos Professores de Joinville” (FUNDAJE, 1967). 
criação da Fundaje, comumente reconhecida como iniciativa exclusiva do poder público municipal. Segundo um dos entrevistados de Collere, a ideia de criar a Fundaje teria surgido num congresso de professores realizado, à época, pela Associação de Professores de Joinville, então presidida por Mário César Moraes, professor de Matemática e Filosofia. Teriam sido eles que levaram ao prefeito o pleito de criação da Faculdade de Filosofia, Ciências e Letras de Joinville (FFCLJ) "para atender à necessidade de formação dos próprios professores" (Collere, 2002, p. 66) que já atuavam nas escolas.

Ao receber a demanda, o prefeito e sua equipe deram-lhe forma e conteúdo, replicando o discurso que, tal como o que fora utilizado para justificar a Fundaje,

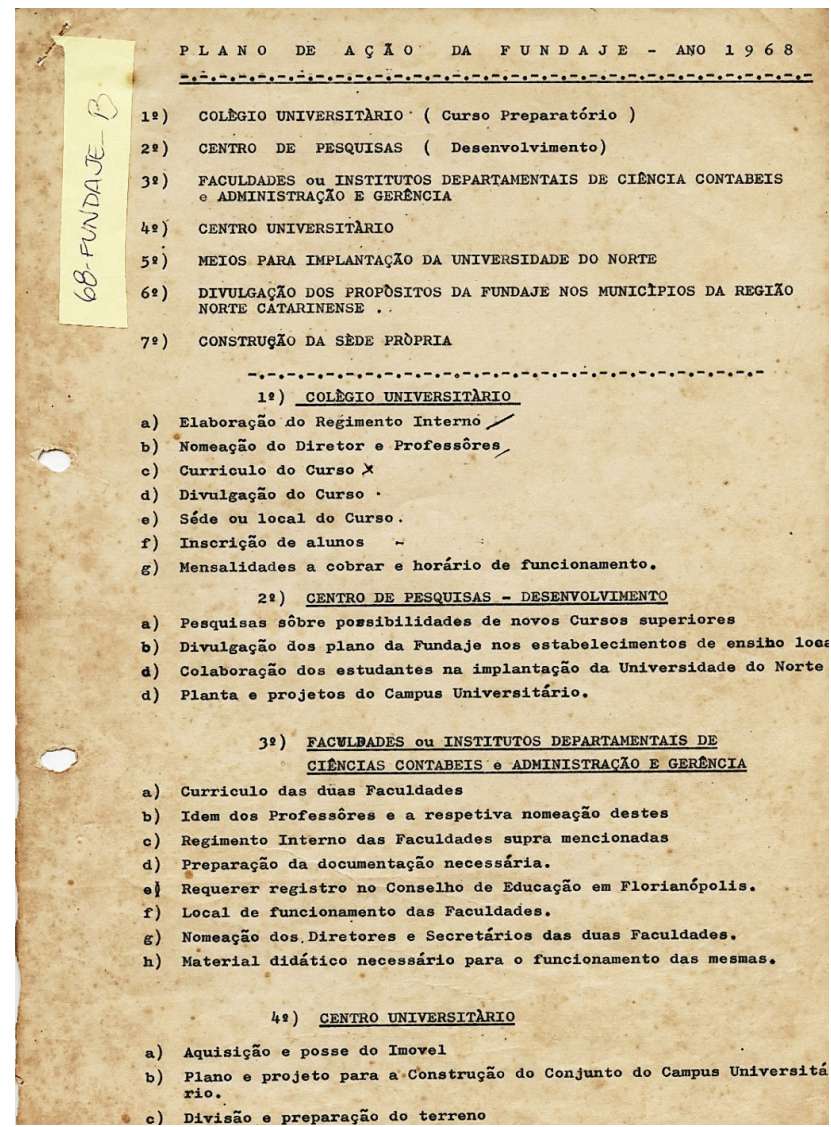

Figura 4 - Fragmento do Plano de Ação da Fundaje para o ano de 1968 (FUNDAJE, 1968)

Fonte: Acervo do Centro Memorial e LHO/Univille. 
destacava a necessidade da FFCLJ para impulsionar o desenvolvimento da cidade e da microrregião por ela polarizada. Nessa direção, tal equipe modulou, formatou e sistematizou a demanda conforme o "Plano de Ação" indicada a seguir (Figura 4):

Prevendo um crescimento de $16,8 \%$ a. a. de escolares apenas no município de Joinville, o documento enviado aos órgãos educacionais que solicitava a autorização da FFCLJ salientava que, para a formação de economistas, engenheiros, administradores e demais técnicos necessários às indústrias, seria mister formar professores para "aprimorar convenientemente discentes de nível primário e médio". Com o curso de Matemática se pretendia obter docentes de Física, Desenho e Matemática, "a fim de dotá-los de recursos culturais suficientes para melhorar os discentes que dependerão sobremaneira das ciências exatas" no ensino superior. $\mathrm{O}$ curso de Letras seria de vital importância numa região que, colonizada por imigrantes de origem alemâ, possuiria uma população com "uma deficiência natural para com o vernáculo pátrio". Os cursos de História e de Geografia iriam dotar os professores para o ensino sobre a "posição geográfica", as "condiçóes climatéricas" e a "variedade e riqueza dos fatos propulsores da colonização e desenvolvimento da regiáo" (Prefeitura de Joinville, 196?, p. 8). Concluía que a FFCLJ era a "grande oportunidade de melhorar horizontes e colaborar com as autoridades constituídas, no sentido de tornar o Brasil mais forte, mais unido, mais capaz" (Prefeitura de Joinville, 196?, p. 9).

Na cerimônia de instalaçáo da FFCLJ, no início de 1968, também ocorreu a posse do primeiro diretor e vice-diretor da Faculdade, professores José Maria Antônio Gomes e Heraldo Ribeiro do Valle. Em seu discurso, o prefeito Nilson Bender destacou a importância do "planejamento científico" para o governo alcançar os objetivos de "interesse da coletividade". Todavia lembrava que "há sempre os que têm preferência pessoal do planejador e do administrador que o manda elaborar". A FFCLJ é apontada como uma de suas preferências, pois the cabia "impulsionar a elevaçáo do nível cultural da classe dirigente de Joinville e proporcionar uma nova perspectiva à mulher joinvilense, a fim de que ela também tivesse oportunidade de frequentar cursos superiores" (Ferreira..., 1968, p. 6).

Ao que as fontes indicam, em seus primeiros quatro anos (1968-1971), a FFCLJ ganhou expressiva quantidade de alunos, passando de 170 para 401 acadêmicos matriculados em quatro cursos superiores de licenciatura (Geografia, História, Letras e Matemática), conforme demonstrado na Figura 5.

Por outro lado, nas atas da Comunidade Evangélica de Joinville de 1969 e 1970 (FUNDAJE, 1969a; 1969b; 1969c; 1970) são registrados debates internos e discordâncias entre professores e corpo diretivo da Fundaje. Contrastando com o elevado número de estudantes matriculados nos cursos de licenciatura, os professores da Fundaje criticavam a falta de infraestrutura para desenvolverem um 
II T R I C U IA

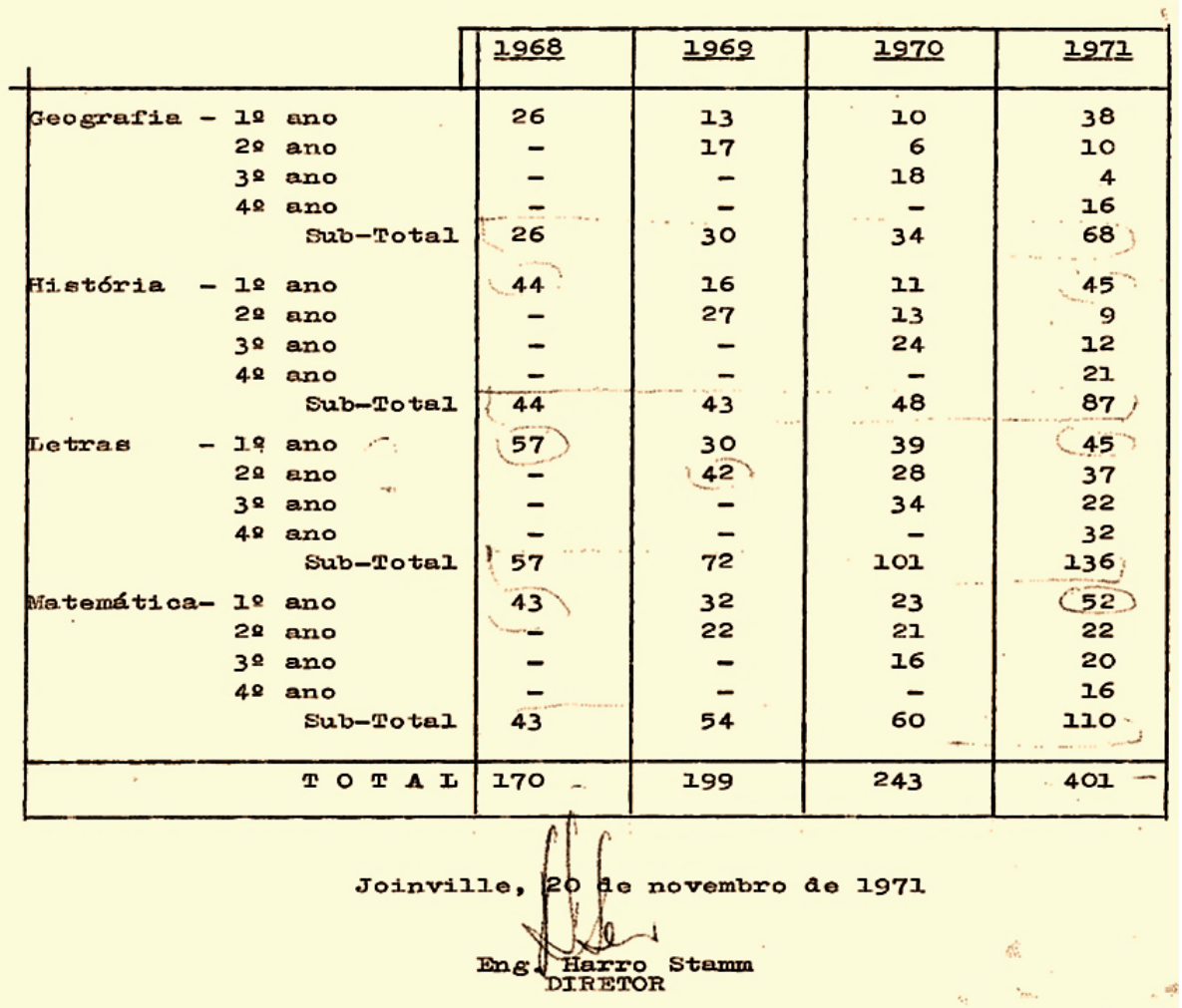

Figura 5 - Alunos matriculados na Faculdade de Filosofia, Ciências e Letras de Joinville (1968-1971)

Fonte: Acervo do Centro Memorial e LHO/Univille.

bom trabalho, reclamavam dos salários que recebiam, além de fazerem críticas à indecisão dos diretores da Fundaje e do prefeito Nilson Bender em encaminhar os trâmites políticos e burocráticos que resultassem na criação de uma nova instituição de ensino superior na regiáo Nordeste catarinense (a Fundaçáo Universidade Regional Norte de Santa Catarina).

$\mathrm{Na}$ ata de 6 de dezembro de 1969 (FUNDAJE, 1969c) há transcrição de uma carta assinada pelo prof. Octávio Melchíades Ulysséa, então coordenador do Centro Superior de Ensino e Pesquisa, endereçada à Fundaje, solicitando seu desligamento da função, já que o Centro teve como meta a integração das 
faculdades (FCEJ, Fundaje e FFCLJ), visando à criação de uma universidade. Segundo ele, apesar de não existir por intermédio de um ato público, a comunidade interna havia trabalhado incansavelmente para sua existência. Alegava que expôs suas críticas à "opinião pública" desejando forçar uma atitude dos responsáveis. Disse, por fim, que duas opçóes estavam dadas à Fundaje: não interferir mais nas faculdades, deixando-as exercer a autonomia que lhes competia como unidades isoladas de ensino superior, ou "criar realmente a Fundação Universidade Regional Norte de Santa Catarina”. O seu pedido de desligamento da função no Centro foi acompanhado por mais dois professores.

Outros professores manifestaram discordância com a direção da Fundaje diante de supostos atos arbitrários e incoerentes com "as reais necessidades" da instituição (FUNDAJE, 1969c). A esse respeito, ainda que de passagem, vale citar o caso de uma professora que exigia maior transparência dos critérios administrativos, visto que ela havia solicitado licença remunerada para fazer pós-graduação, o que lhe foi negado sob alegação de falta de verbas. Contudo, ela soube que a Fundaje iria manter três bolsistas em pós-graduação. Ainda que fossem esclarecidas as razóes que pautaram a direção a prestar apoio aos bolsistas, a situação insinuava certo descompasso interno nas decisóes institucionais, assim como a mobilizaçáo do corpo docente em prol do projeto da universidade e da democratização da gestáo institucional.

Como se nota, o processo de constituição da Fundaje e da FFCLJ contribuiu sobremaneira tanto para a emergência, quanto para o impulso, de novos campos de conhecimento na regiáo, em especial nas cidades de atuação dessas instituiçôes. Resultando em uma embrionária interiorização do ensino superior no estado de Santa Catarina, tal processo foi transpassado por perspectivas de universidade e de formação de professores muito próprias às décadas de 1960 e 1970. É a esse assunto que dedicamos atenção no próximo item deste artigo.

\section{À guisa de conclusão: perspectivas de universidade e de formação de professores}

A configuração institucional da FCEJ, da Fundaje e da FFCLJ, foi, pois, articulada a um contexto histórico que incidia sobre sua identidade pública fundacional e nos objetivos a serem levados a cabo por todas as unidades de ensino à época existentes ou que viriam a ser criadas: capacitar indivíduos para funções econômicas, transmitindo-lhes conteúdos cívicos e pátrios.

Ao que nos parece, foi nessa direçáo que os discursos e as açóes dos dirigentes se articularam ao autoritarismo social (e não apenas de Estado) a que se refere a 
filósofa Marilena Chauí (2001). A autora chama atenção para como a Reforma Universitária de 1968, além de alimentar a ideia de que a cultura acadêmica equivalia à adoção de um "guia prático" para viver corretamente e ascender socialmente, confundiu no âmbito da própria universidade "conhecimento e pensamento". Se conhecimento se refere à apropriação de um "saber estabelecido", pensar seria "enfrentar pela reflexão a opacidade de uma experiência nova" (Chauí, 2001, p. 59).

Nesse âmbito, compreendemos que o trabalho do pensamento é perquirir a novidade da experiência sem se deixar cair na comodidade do saber estabelecido. E, no que se refere à história de uma instituição, pensar implicaria revisitarmos continuamente os restos de seu passado que nos chegam como fragmentos (escritos, orais ou imagéticos) de experiências vividas ou sonhadas. Contudo, não podemos tomar tais experiências como determinações que explicam seus problemas e projetos atuais. Desse ponto de vista, uma história institucional tem por compromisso se mover como uma história "instituinte" e não como um conhecimento instituído (Chauí, 2001, p. 59).

$\mathrm{Na}$ esteira dessa perspectiva foi que procuramos analisar o processo de criaçáo da Fundaje e da FFCLJ, bem como a implantação de seus cursos de licenciatura em Geografia, História, Letras e Matemática. Naquele contexto, pudemos apreender as intençóes que impulsionaram o poder público que, por sua vez, vislumbrava as licenciaturas como recursos indispensáveis para o desenvolvimento econômico da regiáo e da comunidade regional, além de, supostamente, servirem para aprimorar convenientemente discentes de nível primário e médio para contribuir à boa formaçáo de mão de obra especializada, disciplinada e com valores pátrios inculcados.

Por outro lado, isso não coincidia com as expectativas e lutas de professores e professoras envolvidos diretamente na oferta e implementaçáo dos referidos cursos. A documentação nos colocou diante de reivindicaçóes para melhoraria de infraestrutura e salários, bem como para ampliação da qualificação e titulação do quadro docente e implementação de projetos de pesquisa e extensão.

Diante da crise que vem atingindo os cursos de licenciaturas em IES semelhantes à Univille, pensar uma história institucional que seja instituinte seria buscarmos os sinais que brotam de nossas experiências como docentes de licenciaturas, as quais podem insinuar possibilidades de futuro social e da própria universidade para um novo tempo histórico. 


\section{Referências}

AGUIAR, Letícia Carneiro. A interiorização da educação superior no estado de Santa Catarina: a ideia de universidade como discurso de desenvolvimento. Revista HISTEDBR On-Line, Campinas, v. 14, n. 55, p. 213-230, mar. 2014.

ALBERTI, Verena. História oral: a experiência do CPDOC. Rio de Janeiro: FGV, 1990.

AMADO, Janaina; FERREIRA, Marieta de Moraes. Usos e abusos da história oral. Rio de Janeiro: FGV, 1996.

BIELSCHOWSKY, Ricardo. O desenvolvimentismo: do pós-guerra até meados dos anos 1960. In: BIELSCHOWSKY, Ricardo et al. O desenvolvimento econômico brasileiro e a Caixa: palestras. Rio de Janeiro: Centro Internacional Celso Furtado de Políticas para o Desenvolvimento; Caixa Econômica Federal, 2011.

BRASIL. Decreto Federal 64.211, 18 de março de 1969. Autoriza o funcionamento da Faculdade de Ciências Econômicas de Joinville, Santa Catarina. 1969. Disponível em: <https://www2.camara.leg.br/legin/fed/decret/1960-1969/decreto-64211-18-marco1969-405410-publicacaooriginal-1-pe.html >. Acesso em: 22 jul. 2020.

. Ministério da Educação e Cultura. Relatório de autorização para funcionamento. Rio de Janeiro, 30 set. 1968.

. Presidência da República. Ato Institucional n. ${ }^{\circ}$ 1, de 9 de abril de 1964. Dispóe sobre a manutenção da Constituição Federal de 1946 e as Constituiçóes Estaduais e respectivas emendas, com as modificações introduzidas pelo Poder Constituinte originário da revolução Vitoriosa. 1964. Disponível em: <http://www.planalto.gov.br/ ccivil_03/AIT/ait-01-64.htm>. Acesso em: 22 jul. 2020.

CHAUÍ, Marilena de Souza. Escritos sobre a universidade. São Paulo: Unesp, 2001.

COELHO, Ilanil; SOSSAI, Fernando Cesar. Aproximaçóes entre história pública e história oral: o caso do Laboratório de História Oral da Univille. Revista Tempo e Argumento, Florianópolis, v. 8, n. 19, p. 96-129, dez. 2016.

COLLERE, Vanessa de Oliveira. Estudo da adaptação estratégica da Universidade da Região de Joinville - Univille - no período 1965-2001. Dissertaçáo (Mestrado em Engenharia de Produção) - UFSC, Florianópolis, SC, 2002.

FCEJ - FACULDADE DE CIÊNCIAS ECONÔMICAS DE JOINVILLE. Ata da sessão solene de fundação da Faculdade de Ciências Econômicas da Cidade de Joinville. 9 
mar. 1964.

FERREIRA Lima na inauguração da Faculdade de Filosofia de Joinville: universidade brasileira surgiu muito tarde. Jornal de Joinville, Joinville, p. 6, 2 abr. 1968.

FUNDAJE - FUNDAÇÃO JOINVILENSE DE ENSINO. Estatuto da Fundaje. Joinville, 1967.

. Plano de ação da Fundaje - Ano 1968. Joinville, 30 jun. 1968.

. Faculdade de Filosofia, Ciências e Letras de Joinville. Ata $n^{\circ} 6$, reunião da Congregaçáo realizada no dia 7 de junho de 1969a.

. Faculdade de Filosofia, Ciências e Letras de Joinville. Ata $n .^{\circ} 7$, reunião da Congregação realizada no dia 9 de agosto de 1969b.

. Faculdade de Filosofia, Ciências e Letras de Joinville. Ata $n^{\circ} 8$, reunião da Congregação realizada no dia 6 de dezembro de 1969c.

. Faculdade de Filosofia, Ciências e Letras de Joinville. Ata $n^{\circ} 11$, reunião da Congregação realizada no dia 2 de agosto de 1970.

FREUND, Alexander. História oral como processo gerador de dados. Tempos Históricos, Marechal Cândido Rondon, v. 17, n. 2, p. 28-62, 2013.

GERMANO, José Willington. O discurso político sobre a educação no Brasil autoritário. Cadernos Cedes, Campinas, v. 28, n. 76, p. 313-332, set./dez. 2008.

GOULARTI FILHO, Alcides. Formação econômica de Santa Catarina. Florianópolis: Cidade Futura, 2002.

KOSELLECK, Reinhart. Estratos do tempo: estudo sobre História. Rio de Janeiro: Contraponto, 2014.

PORRAS, Juan Daniel Flórez. Guía metodológica para la investigación de historias institucionales. Bogotá: Alcaldía Mayor de Bogotá; Universidad del Rosario, 2011.

PREFEITURA DE JOINVILLE. Consideraçōes sobre a necessidade de implantação de uma Faculdade de Filosofia, Ciências e Letras em Joinville. Joinville, [196?]. Acervo do Centro Memorial da Univille.

TERNES, Apolinário. Bom Jesus: 60 anos de ensino. Joinville: Gráfica Meyer, 1986. 
VALLE, Heraldo Ribeiro Silva do. Consideraçöes sobre a necessidade de implantação de uma Faculdade de Ciências Econômicas em Joinville-SC. Relatório. Joinville, 1968.

\section{Fontes orais}

BENDER, Nilson Wilson. [nov. 1983]. Entrevistadora: Dúnia Anjos de Freitas. Joinville, SC, 20 nov. 1983. Acervo do Laboratório de História Oral - LHO/Univille.

FALLGATTER, Helmuth Ernesto. [set. 1984]. Entrevistadora: Dúnia Anjos de Freitas. Joinville, SC, 24 set, 1984. Acervo do Laboratório de História Oral - LHO/Univille.

SCHÜNEMANN, Achiles Júlio. [mai. 1999]. Entrevistadora: Bellini Meurer. Joinville, SC, 5 mai. 1999. Acervo do Laboratório de História Oral - LHO/Univille.

Resumo: Como se deu o processo de interiorização do ensino superior no norte-nordeste de Santa Catarina? Qual foi o papel dos cursos de formaçáo de professores nesse processo? São essas as questôes que animam este artigo. Tomando como referência os resultados de uma pesquisa sobre a história da Universidade da Região de Joinville (Univille), o texto foi organizado em três partes. Na primeira, analisamos o processo de criação da Faculdade de Ciências Econômicas de Joinville (FCEJ), discutindo as motivaçôes que levaram lideranças políticas, empresariais e educacionais a se envolverem com a oferta de ensino superior naquela região. Em seguida, refletimos sobre os interesses que incidiram na constituição da Fundaçáo Joinvilense de Ensino (Fundaje) e de sua Faculdade de Filosofia, Ciências e Letras de Joinville (FFCLJ) que, a partir de 1968, passaram a oferecer cursos de licenciatura. Por fim, encerramos o artigo com um debate sobre as perspectivas de universidade e formaçáo de professores que, à época, transpassavam a Fundaje e a FFCLJ.

Palavras-chave: História institucional. Formação de professores. Universidade. Univille. Joinville.

\section{Notes on higher education and teacher training in the north and northeast of Santa Catarina (1960-1970)}

Abstract: How did the interiorization process of higher education take place in the north and northeast of Santa Catarina? What was the role of teacher training courses in this process? These are the questions which inspire this article. Taking as a reference the results of research on the history of Universidade da Regiäo de Joinville (Univille), the text was organised in three parts. Firstly, we analysed the process of making of Faculdade de Ciências Econômicas de Joinville (FCEJ), discussing the motivations that stimulated political, business and educational leaders to become involved with the offer of higher education in those regions. After that, we reflected on the interests that affected the constitution of the Fundação Joinvilense de Ensino (Fundaje) and its Faculdade de Filosofia, Ciências e Letras 
(FFCLJ), which, since 1968, started offering undergraduate courses. Finally, we closed the article with a debate on the perspectives of university and teacher training that, at the time, passed through Fundaje and FFCLJ.

Keywords: Institutional history. Teacher training. University. Univille. Joinville.

Recebido em 30/03/20

Aprovado em 17/06/20 